\title{
Improving the outcome of patients with muscle invasive urothelial carcinoma of the bladder with neoadjuvant gemcitabine/cisplatin chemotherapy: A single institution experience
}

\author{
Faraj El-Gehani, MD; ${ }^{*}$ Scott North, MD, FRCPC,+ Sunita Ghosh, PhD; ${ }^{+}$Peter Venner, MD, FRCPC ${ }^{\dagger}$
}

*Department of Oncology, University of Calgary, Calgary, AB; 'Department of Oncology, University of Alberta; and Cross Cancer Institute, Edmonton, AB

Cite as: Can Urol Assoc J 2014;8(3-4):e287-93. http://dx.doi.org/10.5489/cuaj.1643 Published online April 14, 2014.

\section{Abstract}

Introduction: Neoadjuvant cisplatin-based chemotherapy prior to radical cystectomy $(\mathrm{RC})$ for muscle invasive urothelial carcinoma of the bladder improves survival. This study was undertaken to determine the rate of neoadjuvant gemcitabine and cisplatin use prior to RC and to assess its effect on the pathologic response rates and cancer-specific survival (CSS) and overall survival (OS).

Methods: This retrospective chart review examined all patients having a RC between January 1, 2007 and June 30, 2011. We collected patient demographics, pre-treatment clinical stage, type of chemotherapy, post-RC pathologic data and survival data.

Results: A total of 251 RC were performed of which 160 were for stage cT2-T4 urothelial carcinoma of the bladder. Of the 160 patients, 91 (57\%) received neoadjuvant gemcitabine and cisplatin (GC) and 69 (43\%) went straight to RC. Patients receiving neoadjuvant GC had a greater chance of achieving a pathologically lower stage compared to the untreated population: pT0 at $21 \%$ vs. $3 \%$; non-invasive cancer at $37 \%$ vs. $10 \%$; and organ-confined cancer at $60 \%$ vs. $33 \%(p<0.001)$. Survival correlated with pathological stage: $\leq$ pT3a patients had a median OS and CSS of 48.8 and 51.2 months compared to an OS and a CSS in $\geq \mathrm{pT} 3 \mathrm{~b}$ patients of 21.8 and 28.1 months, respectively $(p<0.0001)$.

Conclusions: Neoadjuvant chemotherapy for urothelial carcinoma of the bladder is more frequently administered at our institution compared to the published literature. We have found that neoadjuvant chemotherapy increases the rate of down-staging, which is associated with a reduced the risk of death from urothelial carcinoma of the bladder.

\section{Introduction}

Radical cystectomy (RC) represents the primary therapeutic modality for muscle-invasive (T2-T4) urothelial carcinoma of the bladder. However, it has a $30 \%$ to $50 \%$ recurrence rate if treated with $\mathrm{RC}$ alone, which is likely related to the presence of gross or micro-metastases. ${ }^{1}$
Several studies have shown that neoadjuvant chemotherapy (NAC) increases the probability of eliminating all local disease (pT0) at the time of cystectomy. The frequency of pT0 ranges from $23 \%$ to $38 \%$ in the NAC plus RC group compared to only $12 \%$ to $15 \%$ for RC only. ${ }^{2,3}$ This pathologic down-staging translates into improved survival. ${ }^{4}$ Clinical trials and subsequent meta-analyses have shown that NAC prior to RC is associated with $5 \%$ to $8 \%$ improvement in overall survival compared to RC alone. ${ }^{4-6} \mathrm{~A}$ metaanalysis of individual patient data from 11 trials involving 3005 urothelial carcinoma of the bladder patients found a significant survival benefit associated with platinum-based NAC, with a $14 \%$ reduction in the risk of death and a $5 \%$ absolute improvement in survival at 5 years. ${ }^{6}$

Despite strong evidence and clinical practice guidelines recommending NAC prior to $\mathrm{RC}$, it remains low at $<20 \%$ in North America regardless of whether the patient is treated in an academic or community centre. ${ }^{7,8}$ Although there may be medical contraindications for cisplatin-based NAC, the decision regarding its appropriateness should be made in consultation with a medical oncologist even though referrals to a medical oncologist are too low. ${ }^{9}$

Traditionally, the NAC regimen for urothelial carcinoma of the bladder is a combination of methotrexate, vinblastine, doxorubicin, and cisplatin (MVAC), which was the regimen used in the SWOG phase III randomized trial NAC. ${ }^{4}$ MVAC is an effective regimen in this setting in terms of pathologic down-staging and survival; however, it has an unfavourable toxicity profile, producing significant (grade $\geq 3$ ) hematologic and non-hematologic toxicities. ${ }^{4}$ In contrast, a combination of gemcitabine and cisplatin (GC) has an improved side effect profile compared to MVAC. ${ }^{10}$ Currently, GC in the neoadjuvant setting is based on data extrapolated from the metastatic setting, as only few retrospective series have reported on administering neoadjuvant chemotherapy GC. ${ }^{2,11}$

To further define the role of neoadjuvant chemotherapy GC, we conducted a single-institution, retrospective study to determine its referral rates, the proportion of patients receiv- 
ing it and its effect on pathologic down-staging at time of RC and on overall survival (OS) and cancer-specific survival (CSS).

\section{Methods}

Following research ethics board approval, we retrospectively reviewed charts from the Alberta Urology Institute Radical Cystectomy Database (a prospectively collected surgical database) ${ }^{12}$ for all patients undergoing a RC between January 1, 2007 and June 30, 2011. Patients with T2-T4 urothelial carcinoma of the bladder were considered eligible to receive NAC. Patients with $\mathrm{cN}+$ disease were not included. Data collected included patient demographics, indications for $\mathrm{RC}$, clinical stage (based on clinical exam and computed tomography imaging), use of $\mathrm{NAC}$, pathological stage at time of RC, surgeon performing RC, overall survival, reason why NAC was not administered and the type and dose of chemotherapy administered.

The primary exposure variable was NAC use (either patients had it or not). The primary outcome was the incidence of down-staging as defined as RC pathologic stage compared to the clinical stage using the TNM Classification of Malignant Tumours (version 7). The degree of down-staging at the time of RC was categorized using 3 thresholds: complete down-staging (i.e., pTON0); non-invasive downstaging (i.e., residual cancer of pTis/pTa/pT1 and pN0); and organ-confined disease $(\leq \mathrm{pT} 3 \mathrm{a}$ and $\mathrm{pN} 0)$. Patients with $\mathrm{pT} 3 \mathrm{~b}$ to $\mathrm{pT} 4 \mathrm{~b}$ and any patients with $\mathrm{pN}+$ disease were classified as having non-organ confined disease. ${ }^{3,13}$ The secondary outcome determined was OS and CSS stratified by treatment (NAC vs. no NAC) and pathological stage.

The chemotherapy treatment plan consisted of 4 cycles of gemcitabine combined with cisplatin over a 21-day cycle, with gemcitabine administered on days 1 and $8(1250 \mathrm{mg} /$ $\left.\mathrm{m}^{2}\right)$ and cisplatin administered on day $1\left(70 \mathrm{mg} / \mathrm{m}^{2}\right)$.

Descriptive statistics were obtained for categorical and continuous variables. The mean and standard deviation were reported for continuous variables and frequencies for categorical variables. Chi-square test statistics were used to compare the categorical variables. OS and CSS were defined as the time from pathologic confirmation of disease until death; patients who were alive at the end of the followup were considered censored. OS and CSS survival were calculated using the Kaplan-Meier estimator. Log-rank test statistics were used to compare the survival outcomes among different groups. Hazard ratio and the corresponding 95\% confidence interval for survival were obtained using Cox's proportional hazard model. All statistical analyses were conducted using SAS software version 9.3 (SAS Institute Inc., Cary, NC) and a $p$ value $\leq 0.05$ was considered statistically significant.

\section{Results}

During the study period, a total of 251 RCs were performed. Of these, 160 patients had muscle-invasive, non-metastatic urothelial carcinoma of the bladder and considered potential NAC candidates. Of the 160 patients, 69 (43\%) went straight to RC (i.e., they were untreated with NAC) and the remaining 91 (57\%) received NAC (i.e., the treated group). Patients did not receive NAC for the following reasons: $13 \%$ patient choice, 33\% no referral to medical oncology and in $55 \%$ there was a medical contraindication (Fig. 1). These included $46 \%$ with inadequate renal function, $16 \%$ poor performance status, $16 \%$ heart disease, $14 \%$ large urinary bladder mass with ureteral obstruction, $5 \%$ fistula formation and $3 \%$ due to rapidly progressing disease.

\section{Baseline demographics}

The characteristics of the NAC candidates are described in Table 1. The untreated group was older with a mean age of 72 years compared to 65 years for the treated group $(p<0.0001)$. The male to female patient ratio was not different between the treated and untreated groups ( $p=0.6449)$. The pre-treatment clinical stage was different in the 2 groups: $45 \%$ in the treated group were $\geq \mathrm{cT} 3$ compared to only $22 \%$ of patients in the untreated group $(p=0.0003)$.

In total, 91 patients received NAC. Cisplatin-based NAC was delivered to $82(90 \%)$, carboplatin-based NAC to $7(8 \%)$ and $2(2 \%)$ started on cisplatin and then switched to carboplatin due to toxicities. Initially, the protocol called for 3 cycles of chemotherapy instead of the now standard 4; 16 patients received only 3 cycles. Twelve patients had the chemotherapy stopped because of toxicity; 5 patients had fewer than 4 cycles of chemotherapy because of progressive disease on interim imaging and ultimately they proceeded to RC.

The time between the transurethral resection of the bladder tumour and the RC was significantly longer in the treated group compared to the untreated group (159 days vs. 78 days, $p<0.0001$ ).

Patients underwent an extended pelvic lymph node dissection in association with RC. The median number of lymph nodes removed was 12 .

\section{Down-staging}

The proportion of patients completely down-staged at RC (pT0) was higher in the treated group compared with untreated group, $21 \%(19 / 91)$ vs. $3 \%(2 / 69)(p=0.001)$ (Table 2$)$. In addition, in the treated group the proportion of patients with $<$ pT2 disease was $37 \%$ compared to $10 \%$ in the untreated group ( $p=0.0001)$ and the proportion of patients downstaged to organ-confined disease was also greater in the NAC group (60\% vs. $33 \%, p=0.0006)$. 


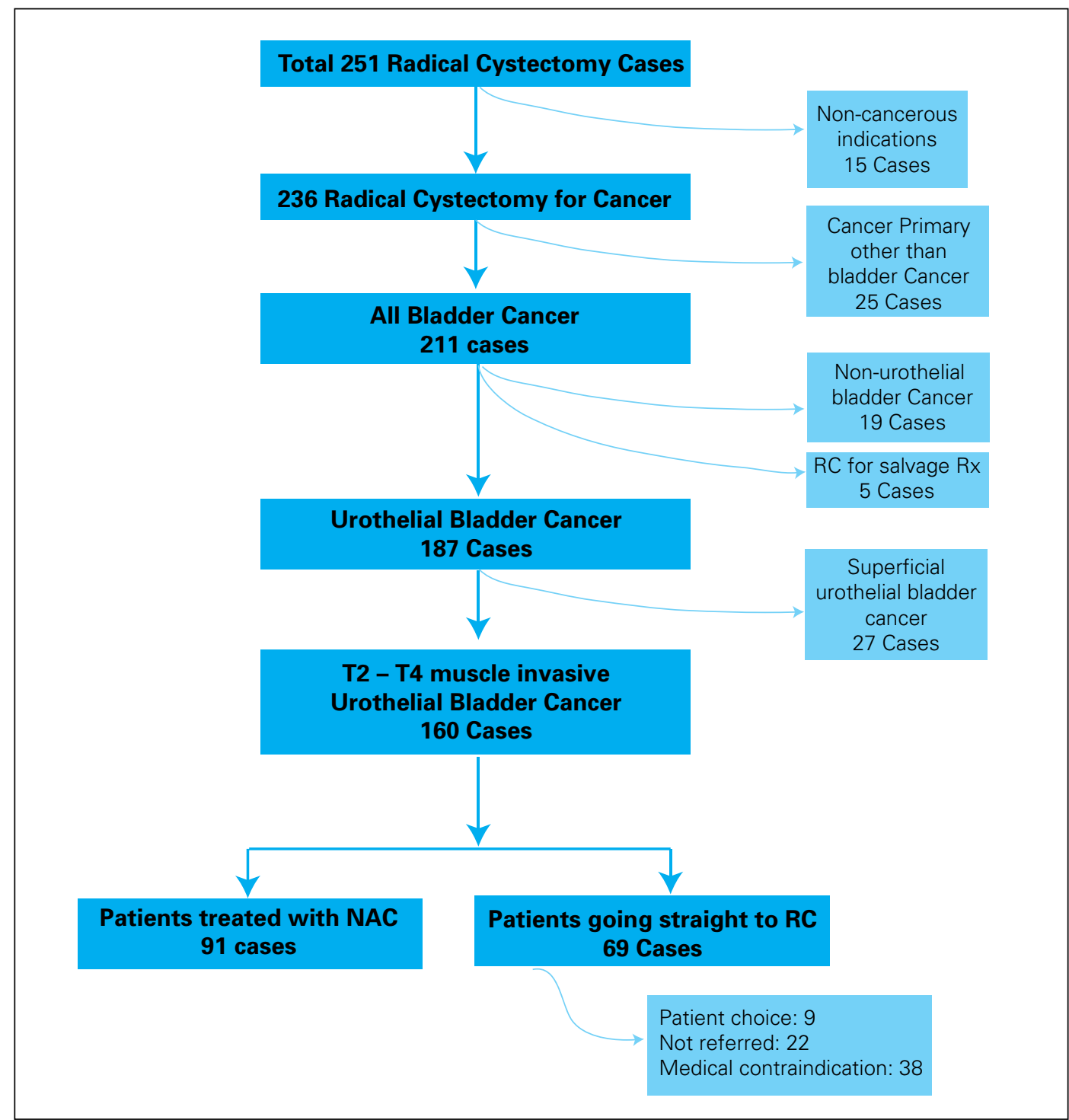

Fig. 1. Consort diagram shows the study cohort of 251 patients undergoing radical cystectomy between January 1, 2007 and June 30, 2011.

Overall, $28 \%$ of the patients were $\mathrm{pN}+$ and although there was a trend to a reduction in $\mathrm{pN}+$ disease in the NAC group, there was no statistically significant difference in the frequency of lymph node metastases between the treated group and the untreated group $(24 \%$ vs. $33 \%, p=0.09$.

In the untreated group, $13 / 69$ (19\%) subsequently received adjuvant GC chemotherapy after the RC.

\section{Survival and pathological stage}

The median follow-up was 34 months (range: 6.4-84.6) for the treated group and 22.1 months (range: 1.7-74.6) for the untreated group. For all 160 patients, the median OS was 41.1 months and the median CSS was not reached (Fig. 2). The median OS of the NAC group was 51.2 months, compared to 24.1 months for the untreated group (hazard ratio [HR] 0.67; 95\% confidence interval [CI] 0.44-1.04, $p=0.07)$. The median duration of CSS of the NAC treated group was not reached compared to 39.3 months for the untreated patients (Fig. 3) (HR 0.70; 95\% Cl 0.43-1.14, $p=0.15$.

Patients with organ-confined urothelial carcinoma of the bladder had a longer median OS compared to those with non-organ confined disease (48.8 vs. 21.7 months; HR $0.55 ; 95 \% \mathrm{Cl} 0.32-0.94, p=0.03)$. They also had a longer CSS (51.2 vs. 28.1 months; HR 0.60; 95\% Cl 0.34-1.07, $p=0.08$ ) (Fig. 4). The outcome of patients more specifically correlated with the actual pathological stage; in patients with pT0 and pT1 disease, the median OS has not been reached, compared to 48.8 months for $\mathrm{pT} 2 / \mathrm{pT} 3$ a patients 


\begin{tabular}{|c|c|c|c|}
\hline & $\begin{array}{c}\text { Neoadjuvant } \\
\text { chemotherapy } \\
n=91\end{array}$ & $\begin{array}{c}\text { No neoadjuvant } \\
\text { chemotherapy } \\
n=69\end{array}$ & $p$ value \\
\hline $\begin{array}{l}\text { Age (yr) } \\
\text { Mean/Range }\end{array}$ & 65 (48-89) & $72(50-89)$ & $<0.0001$ \\
\hline $\begin{array}{l}\text { Gender, no. (\%) } \\
\text { Male } \\
\text { Female }\end{array}$ & $\begin{array}{l}67(74 \%) \\
24(26 \%)\end{array}$ & $\begin{array}{l}53(77 \%) \\
16(23 \%)\end{array}$ & 0.6449 \\
\hline $\begin{array}{l}\text { Clinical stage, no. (\%) } \\
\text { T2 } \\
\text { T3 } \\
\text { T4 }\end{array}$ & $\begin{array}{c}50(55 \%) \\
38(42 \%) \\
3(3 \%)\end{array}$ & $\begin{array}{c}54(78 \%) \\
9(13 \%) \\
6(9 \%)\end{array}$ & 0.0003 \\
\hline
\end{tabular}

and 21.7 months for $\geq$ pT3b and or $\mathrm{N}+$ disease (Table 3) (Fig. 5). This was similar for CSS with the median survival not being reached in the patients with pT0 and pT1 cancers compared to a median survival of 51.2 months in the pT2/ pT3a group and 28.1 months in the $\geq$ pT3b and or $N+$ group (Table 4) (Fig 5).

The outcome for patients with pathological involvement of the lymph nodes was similar whether or not they received NAC (Fig. 6). The OS for patients with ypNO and pNO was not reached and was not significantly different $(p=0.13)$. The OS for patients with ypN+ or $\mathrm{pN}+$ disease was, respectively, 20.8 and 17.8 months ( $p=0.57)$; CSS was 23.7 and 22.1 months $(p=0.85)$, respectively. The median OS for patients with $\mathrm{pN} 0, \mathrm{pN} 1, \mathrm{pN} 2$ and $\mathrm{pN} 3$ disease was 55.8, $21.2,19.0$ and 16.6 months, respectively $(p<0.0001)$.

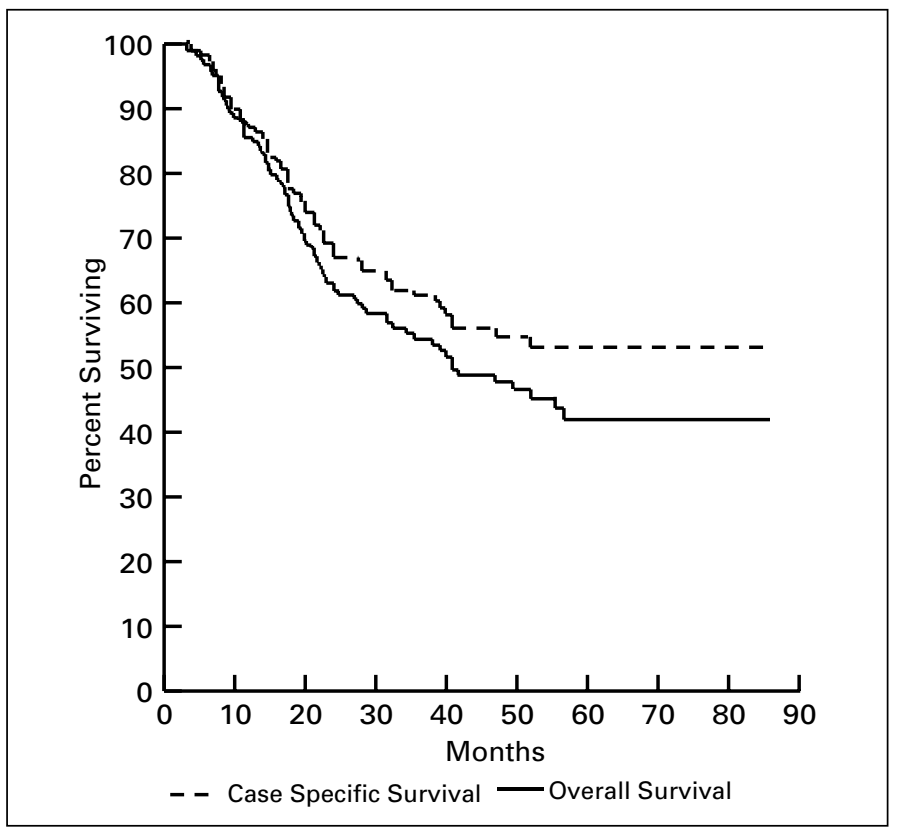

Fig. 2. Kaplan-Meier curve of overall survival and cancer specific survival estimates for all 160 patients undergoing a radical cystectomy for muscle invasive bladder cancer.

\begin{tabular}{lccc}
\hline \multicolumn{4}{l}{$\begin{array}{l}\text { Table 2. Pathologic stage of all } \\
\text { radical cystectomy patients undergoing a }\end{array}$} \\
\hline $\begin{array}{l}\text { Pre-cystectomy } \\
\text { clinical stage }\end{array}$ & $\begin{array}{c}\text { Neoadjuvant } \\
\text { chemotherapy }\end{array}$ & $\begin{array}{c}\text { No neoadjuvant } \\
\text { chemotherapy }\end{array}$ & $p$ value \\
\hline \multicolumn{4}{c}{ Complete down-staging } \\
T2 & $12 / 50(24 \%)$ & $2 / 54(4 \%)$ & 0.002 \\
T3 & $7 / 38(18 \%)$ & $0 / 9(0 \%)$ & 0.163 \\
T4 & $0 / 3(0 \%)$ & $0 / 6(0 \%)$ & - \\
ALL & $19 / 91(21 \%)$ & $2 / 69(3 \%)$ & 0.001 \\
\multicolumn{4}{c}{ Non-invasive cancer } \\
T2 & $22 / 50(44 \%)$ & $7 / 54(13 \%)$ & 0.0004 \\
T3 & $11 / 38(29 \%)$ & $0 / 9(0 \%)$ & 0.065 \\
T4 & $1 / 3(33 \%)$ & $0 / 6(0 \%)$ & 0.133 \\
ALL & $34 / 91(37 \%)$ & $7 / 69(10 \%)$ & 0.0001 \\
& Organ confined cancer & \\
T2 & $33 / 50(66 \%)$ & $20 / 54(37 \%)$ & 0.003 \\
T3 & $20 / 38(53 \%)$ & $2 / 9(22 \%)$ & 0.100 \\
T4 & $2 / 3(67 \%)$ & $1 / 6(17 \%)$ & 0.134 \\
ALL & $55 / 91(60 \%)$ & $23 / 69(33 \%)$ & 0.0006 \\
\hline
\end{tabular}

The CSS for patients with $\mathrm{pN} 0$ and $\mathrm{pN} 1$ disease was not reached; for $\mathrm{pN} 2$ and $\mathrm{pN} 3$, the CSS was 19.2 and 19.7 months, respectively (Fig. 7).

\section{Influence of urological surgeon}

The 160 radical cystectomies were performed by 6 urologists. Analyses based on the individual surgeons for referral rates for NAC and outcomes based on OS did not reveal any significant difference between the surgeons (data not shown).

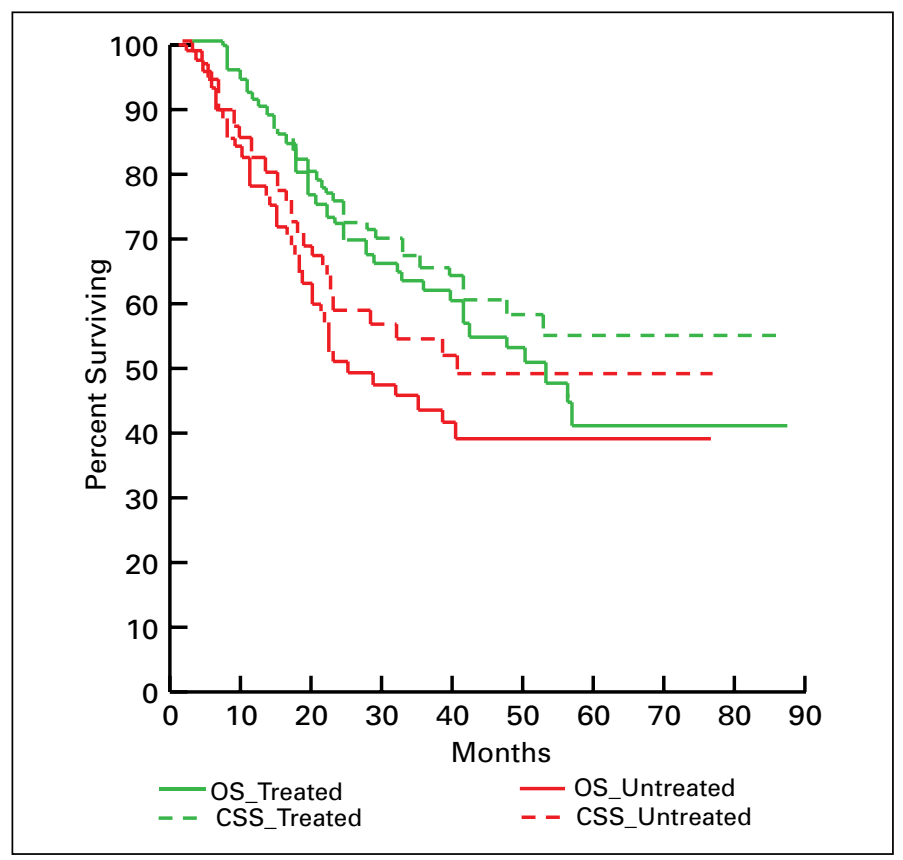

Fig. 3. Kaplan-Meier curve of overall survival and cancer specific survival estimates of patients receiving or not receiving neo-adjuvant chemotherapy. 


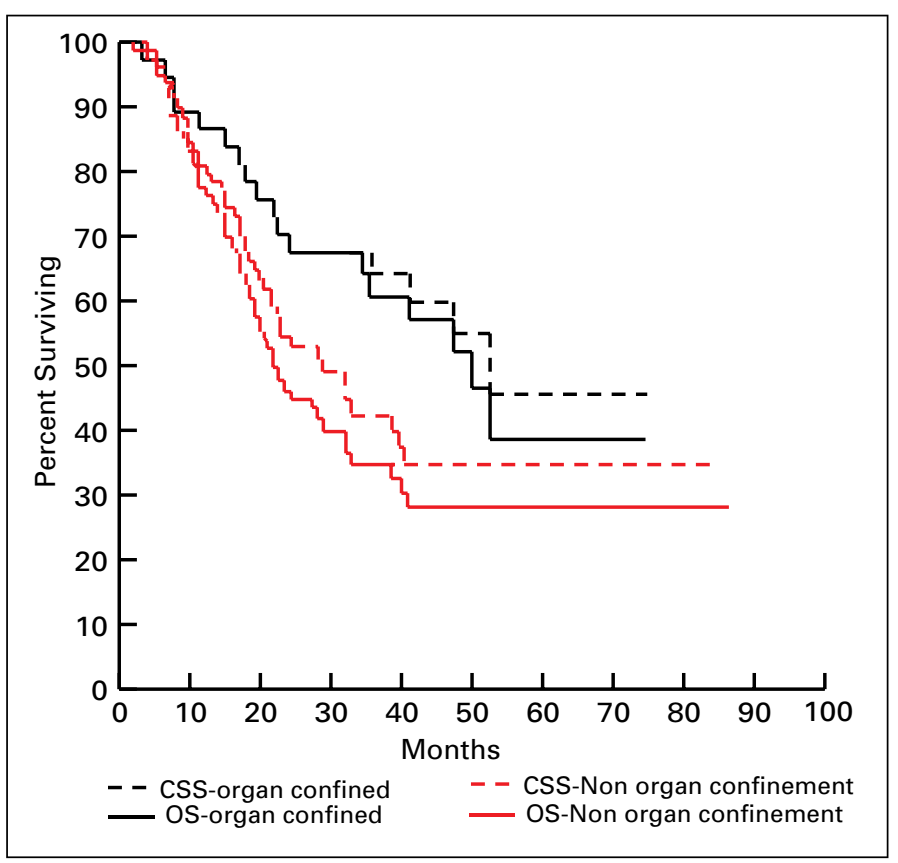

Fig. 4. Kaplan-Meier curve of overall survival and cancer specific survival estimates of patients based on organ confinement or not at the time of radical cystectomy.

\section{Discussion}

In North America, RC is the standard treatment for muscleinvasive (T2-T4) urothelial carcinoma of the bladder; alone it is only associated with 5-year survival rates of $57 \%$ to $68 \%{ }^{7,8}$ Studies have shown that cisplatin-based NAC followed by RC is associated with a $5 \%$ to $8 \%$ improved survival and a $14 \%$ to $16 \%$ reduction in risk of death compared to RC alone. ${ }^{4-6,14}$ Despite strong evidence to support the use of NAC in urothelial carcinoma of the bladder, its use remains dismal. ${ }^{4}$ While earlier studies have shown that only $1 \%$ to $5 \%$ of bladder cancer patients received NAC, there does appear to be a small increase in the use of NAC since 2003 , with rates increasing to $12 \%$ to $19 \%$., 915,16

In this series, 91/113 (80\%) of potentially eligible patients received NAC (Fig. 1). The high rate of NAC may due to the increased awareness of the urological oncology community of the importance of NAC in urothelial carcinoma of the

Table 3. Overall survival hazard ratios based on pathological stage at the time of radical cystectomy

\begin{tabular}{llcc}
\hline Stage & HR & 95\% Cl & $p$ value \\
\hline pT0 vs. pT2/pT3a & 0.35 & $0.14-0.99$ & 0.05 \\
pT0 vs. $>$ pT3b & 0.20 & $0.08-0.50$ & $<0.0001$ \\
pT1 vs. pT2/pT3a & 0.42 & $0.15-1.12$ & 0.08 \\
pT1 vs. >pT3b and/or N+ & 0.23 & $0.10-0.57$ & 0.002 \\
\hline HR: hazard ratio; Cl: confidence interval. & & \\
\hline
\end{tabular}

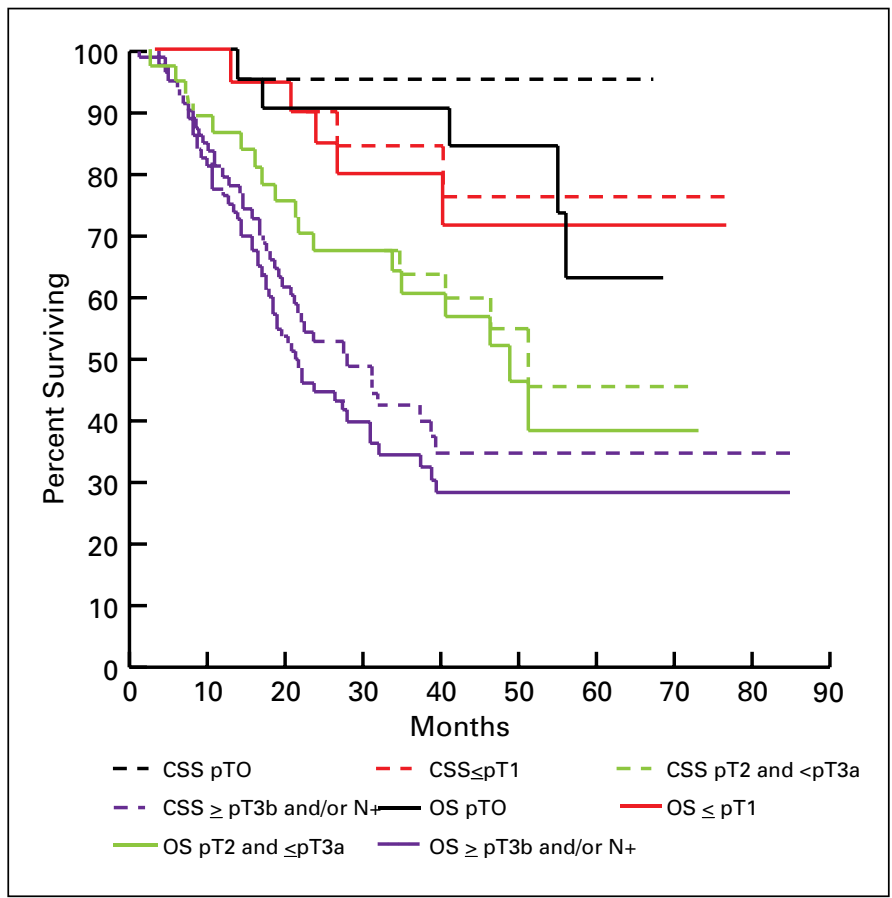

Fig. 5. Kaplan-Meier curve of overall survival and cancer specific survival estimates of patients based on pathological stage at the time of radical cystectomy.

bladder, a centralized referral system with excellent communication between specialties, recognition that chemotherapy can be given safely to properly selected patients, and a commitment from medical oncologists to ensure rapid time to consultation, chemotherapy delivery and referral back for RC. A multidisciplinary care approach and implementation of the clinical practice guidelines have helped to change the practice. ${ }^{9}$

The time to RC for the NAC group was 81 days longer, which is only slightly longer than the time needed to deliver a 10-week NAC program. Therefore, there does not appear to be undue delays in time to RC due to medical oncology referral or recovery from NAC toxicities.

A cisplatin-based regimen, which requires adequate renal function, should be the standard in the NAC setting. Initially when NAC started to be given at our institution, some patients were treated with carboplatin because of the

$\begin{aligned} & \text { Table 4. Cancer-specific survival hazard ratios based on } \\
& \text { pathological stage at the time of radical cystectomy }\end{aligned}$
\begin{tabular}{llcc} 
Stage & HR & $\mathbf{9 5 \%}$ Cl & p value \\
\hline pT0 vs. pT2/pT3a & 0.10 & $0.01-0.64$ & 0.02 \\
pT0 vs. $\geq$ pT3b & 0.10 & $0.01-0.37$ & 0.003 \\
pT1 vs. pT2/pT3a & 0.38 & $0.13-1.14$ & 0.09 \\
pT1 vs. >pT3b and/or N+ & 0.23 & $0.08-0.64$ & 0.005 \\
\hline HR: hazard ratio; Cl: confidence interval. & & & \\
\hline
\end{tabular}




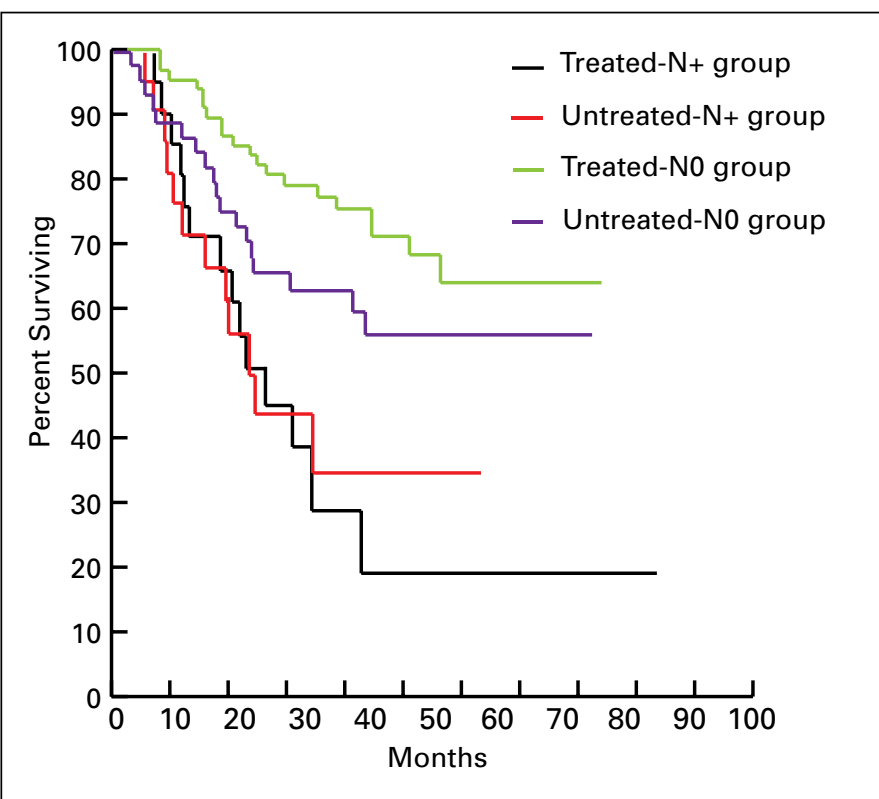

Fig. 6. Kaplan-Meier curve of cancer specific survival estimates of patients based on presence or absence of lymph node metastases receiving NAC or going straight to $\mathrm{RC}$.

perceived need to administer some form of NAC. This practice was subsequently abandoned as there was no evidence from randomized studies demonstrating the equivalence of carboplatin to cisplatin in this setting. However, a recent report suggests that carboplatin combined with gemcitabine maybe a reasonable alternative to the cisplatin combination and should be considered when the latter cannot be administered. ${ }^{17}$ Generally, in both clinical trials and standard practice, cisplatin-based NAC is given only to patients with glomerular filtration rates (GFR) of at least $60 \mathrm{~mL} / \mathrm{min} / 1.73 \mathrm{~m}^{2}$. This is because bladder cancer patients with a lower GFR $\left(50-59 \mathrm{~mL} / \mathrm{min} / 1.73 \mathrm{~m}^{2}\right)$ showed poorer survival rates compared to those with GFR above $60 \mathrm{~mL} / \mathrm{min} / 1.73 \mathrm{~m}^{2}$ when treated with NAC (cisplatin, methotrexate and vinblastine). ${ }^{18}$ Similar to previous reports, ${ }^{15,19}$ in the $46 \%$ of patients in this series who were ineligible for NAC, the primary reason was inadequate renal function.

This study helps define the role of GC as NAC. In our study, an average of 3.5 cycles of NA GC was delivered ( $88 \%$ of the planned cycles) and $21 \%$ of the treated patients achieved complete response, $37 \%$ non-invasive disease and $60 \%$ organ-confined disease. These findings, which are clinically meaningful and statistically significant, are consistent with other retrospective series that looked at using GC in the neoadjuvant setting. ${ }^{2,3,10,11}$

Pathological stage is an important prognostic factor for patients undergoing RC for bladder cancer. ${ }^{4,20,21}$ Patients with pathologically organ-confined disease at RC (stage $<$ pT3a, $\mathrm{pN} 0$ ) generally have a more favourable prognosis. ${ }^{4,21}$ Median OS for those who achieve stage pT0 was 13.6 years in the sub-analysis of SWOG87-10. ${ }^{20}$ The fact that there is a greater

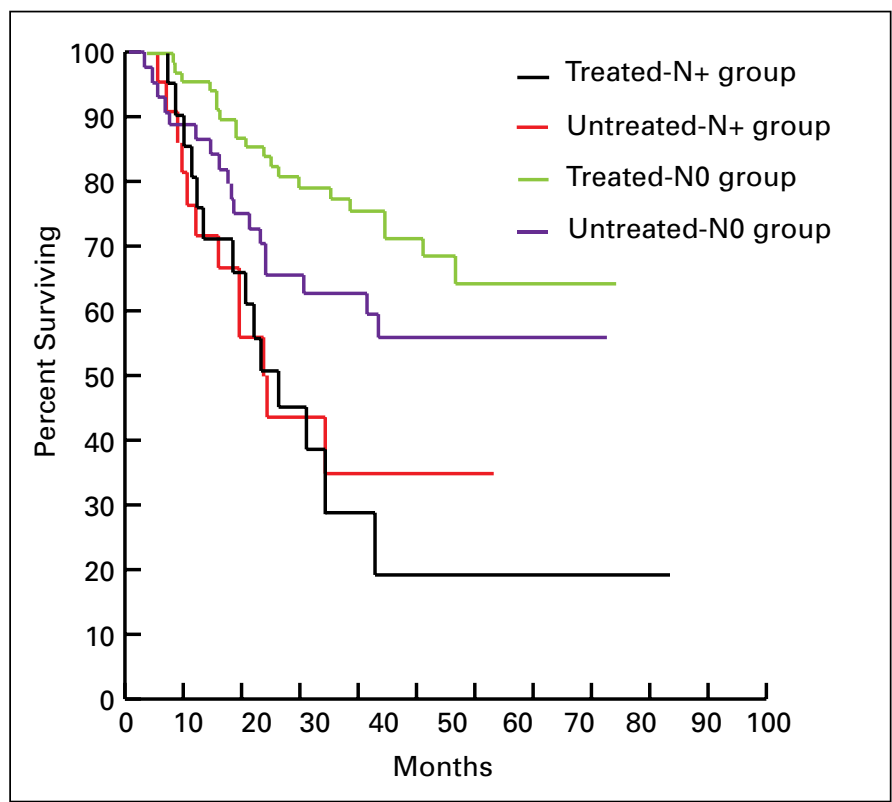

Fig. 7. Kaplan-Meier curve of cause specific survival estimates based on pathological lymph node stage for all patients.

rate of pathologic down-staging with NAC and that lower pathological stage correlates with an improvement in median survival are critical considerations in the management of muscle invasive urothelial carcinoma of the bladder.

More than 3 times as many patients in the NA GC group compared to the untreated group had non-invasive urothelial carcinoma of the bladder. This series also confirms that a pathological lower stage occurs more frequently with NAC $(60 \%$ vs. $33 \%)$ and that a lower stage results in improved survivals (HR 0.54; 95\% Cl 0.32-93). Receiving NAC GC resulted in twice as many patients achieving a non-muscle invasive disease status compared to those that did not receive NA GC ( $42 \%$ vs. $87 \%)$. Based on a comparison of the survival curves for patients with non-invasive disease (pT0 and pT1) to patients with invasive cancer, but organ-confined disease (pT2 and pT3a), there is a $63 \%$ reduced risk of dying $(p=0.01)$; when the non-invasive group is compared to the non-organ confined group (pT3b and or $\mathrm{N}+$ ), there is a $78 \%$ reduction in the risk of death $(p<0.0001)$.

The incidence of lymph node metastases is reduced in the NAC group (24\% vs. $33 \%$ ), although this was not statistically significant. This is similar to a recently reported single institution study examining ypN status in patients undergoing an extended pelvic lymph node dissection post-NAC. ${ }^{22}$ Survival in the present series is related to the absence or presence of lymph node metastases, which is also correlated with clinical stage. NAC did not have a meaningful impact on survival for patients with $\mathrm{pN}+$ disease, but it is possible that $\mathrm{NAC}$ down-staged patients such that the incidence of $\mathrm{pN}+$ disease is reduced which contributes to the improvement in survival observed with NAC. 
Although the median survival is considerably longer in the NAC arm compared to the untreated arm (51 vs. 24 months) and NAC reduces the risk of dying by $33 \%$, the true benefit of NAC may have been attenuated by the fact that $19 \%$ of the untreated group subsequently received adjuvant chemotherapy following their RC.

It is also worthwhile pointing out that considerably more of the patients receiving NA GC in this series had clinical T3/ $\mathrm{T} 4$ disease compared to the patients that did not receive NA GC ( $45 \%$ vs. $22 \%)$ and clinical stage T3/T4 disease is associated with a worse prognosis than T2 disease. ${ }^{12}$ Countering this imbalance of the higher risk patients in the NAC group is the fact that the average age of the NAC treated group was younger, which would be associated with longer OS but not necessarily a longer CSS.

\section{Conclusion}

The real world administration of NAC GC for muscle invasive urothelial carcinoma of the bladder has definite clinical activity with meaningful rates of pathological down-staging, which is associated with an improvement in survival. As GC is a well-tolerated chemotherapy regimen, its utilization in the neoadjuvant setting may encourage the administration of NAC compared to the uptake of MVAC, which should contribute to improved outcomes for patients with muscle invasive urothelial carcinoma of the bladder. Further studies need to be done to identify patients who would need and benefit from NAC.

Competing interests: Dr. El-Gehani, Dr. North, Dr. Ghosh and Dr. Venner all declare no competing financial or personal interests.

This paper has been peer-reviewed.

\section{References}

1. Stein JP, Lieskovsky $G$, Cote $R$, et al. Radical cystectomy in the treatment of invasive bladder cancer: Long-term results in 1,054 patients. J Clin Oncol 2001;19:666-75.

2. Dash A, Peftus JA 4th, Herr HW, et al. A role for neoadjuvant gemcitabine plus cisplatin in muscle-invasive urothelial carcinoma of the bladder: A retrospective experience. Cancer 2008;113:2471-7. http://dx.doi. org/10.1002/cncr.23848

3. Rosenblatt R, Sherif A, Rintala E, et al. Pathologic downstaging is a surrogate marker for efficacy and increased survival following neoadjuvant chemotherapy and radical cystectomy for muscle-invasive urothelial bladder cancer. Eur Urol 2012;61:1229-38. http://dx.doi.org/10.1016/i.eururo.2011.12.010. Epub 2011 Dec 13.

4. Grossman $H B$, Natale RB, Tangen CM, et al. Neoadiuvant chemotherapy plus cystectomy compared with cystectomy alone for locally advanced bladder cancer. N Engl J Med 2003;349:859-66. http://dx.doi. org/10.1056/NEJMoa022148
5. International Collaboration of Trialists, Medical Research Council Advanced Bladder Cancer Working Party (now the National Cancer Research Institute Bladder Cancer Clinical Studies Group), European Organisation for Research and Treatment of Cancer Genito-Urinary Tract Cancer Group et al: International phase III trial assessing neoadjuvant cisplatin, methotrexate, and vinblastine chemotherapy for muscle-invasive bladder cancer: long-term results of the BA06 30894 trial. J Clin Oncol 2011;29:2171-7. http://dx.doi. org/10.1200/JC0.2010.32.3139

6. Advanced Bladder Cancer (ABC) Meta-analysis Collaboration: Neoadjuvant chemotherapy in invasive bladder cancer: Update of a systematic review and meta-analysis of individual patient data advanced bladder cancer (ABC) meta-analysis collaboration. Eur Urol 2005;48:202-6. http://dx.doi.org/10.1016/i. eururo.2005.04.006

7. Bellmunt J, Orsola A, Maldonado X, et al. Bladder cancer: ESMO Practice Guidelines for diagnosis, treatment and follow-up. Ann Oncol 2010;21 (Suppl 5): v134-6. http://dx.doi.org/10.1093/annonc/mdq175

8. National Comprehensive Cancer Care Network: NCCN clinical practice guidelines in oncology: bladder cancer including upper tract tumours and urothelial carcinoma of the prostate. http://www.nccn.org/professionals/physician_gls/f_guidelines.asp\#tbladder (Accessed April 7, 2014; free registration required).

9. Miles BJ, Fairey AS, Eliasziw M, et al. Referral and treatment rates of neoadjuvant chemotherapy in muscle-invasive bladder cancer before and after publication of a clinical practice guideline. Can Urol Assoc J 2010;4:263-7. http://dx.doi.org/10.5489/cuaj09134

10. von der Maase H, Hansen SW, Roberts JT, et al. Gemcitabine and cisplatin versus methotrexate, vinblastine, doxorubicin, and cisplatin in advanced or metastatic bladder cancer: Results of a large, randomized, multinational, multicenter, phase III study. J Clin Oncol 2000;18:3068-77.

11. Kaneko $G$, Kikuchi E, Matsumoto K, et al. Neoadjuvant gemcitabine plus cisplatin for muscle-invasive bladder cancer. Jpn J Clin Oncol 2011;41:908-14. http://dx.doi.org/10.1093/iico/hyr068

12. Fairey AS, Jacobsen NE, Chetner MP, et al. Associations between comorbidity, and overall survival and bladder cancer specific survival after radical cystectomy: Results from the Alberta Urology Institute Radical Cystectomy database. J Urol 2009;182:85-92. http://dx.doi.org/10.1016/i.juro.2008.11.111

13. Gschwend JE, Dahm P, Fair WR. Disease specific survival as endpoint of outcome for bladder cancer patients following radical cystectomy. Eur Urol 2002;41:440-8. http://dx.doi.org/10.1016/S03022838(02)00060-X

14. Sherif A, Holmberg L, Rintala E, et al. Neoadjuvant cisplatinum based combination chemotherapy in patients with invasive bladder cancer: A combined analysis of two Nordic studies. Eur Urol 2004;45:297-303. http://dx.doi.org/10.1016/i.eururo.2003.09.019

15. Raj GV, Karavadia S, Schlomer B, et al. Contemporary use of perioperative cisplatin-based chemotherapy in patients with muscle-invasive bladder cancer. Cancer 2011;117:276-82. http://dx.doi.org/10.1002/ cncr.25429

16. Bajorin DF, Herr HW. Kuhn's paradigms: Are those closest to treating bladder cancer the last to appreciate the paradigm shift? J Clin Oncol 2011;29:2135-7. http://dx.doi.org/10.1200/JC0.2010.34.0471

17. Mertens $L S$, Meijer RP, Kerst JM, et al. Carboplatin based induction chemotherapy for nonorgan confined bladder cancer-a reasonable alternative for cisplatin unfit patients? J Urol 2012;188:1108-14. http:// dx.doi.org/10.1016/i.juro.2012.06.018

18. Neoadjuvant cisplatin, methotrexate, and vinblastine chemotherapy for muscle-invasive bladder cancer: A randomised controlled trial. International collaboration of trialists. Lancet 1999;354:533-40. httr:// dx.doi.org/10.1016/S0140-6736(99)02292-8

19. Canter D, Viterbo R, Kutikov A, et al. Baseline renal function status limits patient eligibility to receive perioperative chemotherapy for invasive bladder cancer and is minimally affected by radical cystectomy. Urology 2011;77:160-5. http://dx.doi.org/10.1016/i.urology.2010.03.091

20. Sonparde G, Goldman BH, Speights V0, et al. Quality of pathologic response and surgery correlate with survival for patients with completely resected bladder cancer after neoadjuvant chemotherapy. Cancer 2009;115:4104-9. http://dx.doi.org/10.1002/cncr.24466

21. Dalbagni $G$, Genega E, Hashibe $M$, et al. Cystectomy for bladder cancer: A contemporary series. J Urol 2001;165:1111-6. http://dx.doi.org/10.1016/S0022-5347(05)66440-3

22. Mertens LS, Meijer RP, Meinhardt W, et al. Occult lymph node metastases in patients with muscle invasive bladder cancer: Incidence after neoadjuvant chemotherapy and cystectomy versus cystectomy alone. BJU Int 2013. http://dx.doi.org/10.1111/bju.12447

Correspondence: Dr. Peter Venner, Department of Oncology, University of Calgary, Calgary, AB; peter.venner@albertahealthservices.ca 